\title{
BMJ Early life bereavement and childhood Open cancer: a nationwide follow-up study in two countries
}

\author{
Natalie C Momen, ${ }^{1}$ Jørn Olsen, ${ }^{1,2}$ Mika Gissler, ${ }^{3,4}$ Sven Cnattingius, ${ }^{5}$ Jiong Li ${ }^{1}$
}

To cite: Momen NC, Olsen J, Gissler M, et al. Early life bereavement and childhood cancer: a nationwide followup study in two countries. BMJ Open 2013;3:e002864. doi:10.1136/bmjopen-2013002864

- Prepublication history for this paper are available online. To view these files please visit the journal online (http://dx.doi.org/10.1136/ bmjopen-2013-002864).

Received 11 March 2013 Revised 18 April 2013 Accepted 29 April 2013

This final article is available for use under the terms of the Creative Commons Attribution Non-Commercial 2.0 Licence; see http://bmjopen.bmj.com

${ }^{1}$ Section for Epidemiology, Department of Public Health, Aarhus University, Aarhus, Denmark

${ }^{2}$ Department of

Epidemiology, University of California, Los Angeles,

California, USA

${ }^{3}$ Department of Information, THL National Institute for Health and Welfare, Helsinki, Finland

${ }^{4}$ Nordic School of Public Health NHV, Gothenburg, Sweden

${ }^{5}$ Department of Medical Epidemiology and Biostatistics, Karolinska Institute, Stockholm, Sweden

Correspondence to Natalie C Momen; nataliem@soci.au.dk

\section{ABSTRACT}

Objective: Childhood cancer is a leading cause of child deaths in affluent countries, but little is known about its aetiology. Psychological stress has been suggested to be associated with cancer in adults; whether this is also seen in childhood cancer is largely unknown. We investigated the association between bereavement as an indicator of severe childhood stress exposure and childhood cancer, using data from Danish and Swedish national registers.

Design: Population-based cohort study.

Setting: Denmark and Sweden.

Participants: All live-born children born in Denmark between 1968 and 2007 ( $n=2729$ 308) and in Sweden between 1973 and 2006 ( $n=3395$ 166) were included in this study. Exposure was bereavement by the death of a close relative before 15 years of age. Follow-up started from birth and ended at the first of the following: date of a cancer diagnosis, death, emigration, day before their 15th birthday or end of follow-up (2007 in Denmark, 2006 in Sweden).

Outcome measures: Rates and HRs for all childhood cancers and specific childhood cancers.

Results: A total of 1505938 (24.5\%) children experienced bereavement at some point during their childhood and 9823 were diagnosed with cancer before the age of 15 years. The exposed children had a small $(10 \%)$ increased risk of childhood cancer (HR $1.10 ; 95 \% \mathrm{Cl} 1.04$ to 1.17). For specific cancers, a significant association was seen only for central nervous system tumours (HR 1.14; $95 \% \mathrm{Cl} 1.02$ to 1.28).

Conclusions: Our data suggest that psychological stress in early life is associated with a small increased risk of childhood cancer.

\section{INTRODUCTION}

Childhood cancer is a leading cause of child deaths in affluent societies. ${ }^{12}$ Almost half of childhood cancers are diagnosed before 5 years of age,,$^{2}$ highlighting the importance of identifying early life risk factors for developing prevention strategies ${ }^{2}{ }^{3}$ but, in comparison to adult cancers, known risk factors are few. ${ }^{4}$ Additionally, heterogeneity and

\section{ARTICLE SUMMARY}

\section{Article focus}

- There is limited information on the aetiology of childhood cancers, and psychological stress may play a role.

- We investigated the association between psychological stress following bereavement by the death of a close relative early in life and subsequent childhood cancer.

Key messages

- A small $(10 \%)$ increase in the risk of childhood cancer was seen among those who experienced the death of a close relative.

- The association between early life stress and childhood cancer was small, but adds to our understanding of the causes of childhood cancers.

Strengths and limitations of this study

- The study utilises high-quality nationwide registers in two countries. Large sample sizes are important because of the rareness of childhood cancer.

- There are probably other sources of stress on which we do not have information, but the death of a close relative is considered to be one of the most stressful experiences, which will provide a large exposure contrast.

- The limited information on the aetiology of childhood cancers means that confounder control is incomplete.

rareness of childhood cancers make investigation in populations challenging.

Studies in adults have reported increased cancer risks following psychological stress. ${ }^{6} 7$ Psychological stress activates the nervous system and the hypothalamic-pituitaryadrenal axis, leading to release of hormones such as glucocorticoids and norepinephrine. Research has shown stress and the subsequent hormonal dysfunction can lead to impairment of DNA repair ${ }^{8}$ and suppression of the immune response. ${ }^{9}$ Additionally, stress may lead to epigenetic silencing: altering DNA methylation and histone acetylation, ${ }^{10}$ 
which are important during tumour development. ${ }^{11-13}$

Little is known about the effect of stress in early postnatal life on the risk of childhood cancers and the effect of stress is potentially a much more complex exposure in children than in adults. First, children have immature body systems; growth and differentiation of their organs can be disrupted, ${ }^{14}$ potentially increasing susceptibility to environmental exposures. Through its effects on immune function, stress may increase susceptibility to infections, which have also been linked to certain childhood cancers. ${ }^{15-18}$ However, 'resilience to adversity' ${ }^{19}$ might imply that stress may not lead to the same hormonal and immunological disturbances observed in adults. Our previous work on psychological stress in adults uses bereavement, considered to be one of the most stressful experiences, ${ }^{20}$ as an indicator for psychological stress. ${ }^{6}{ }^{21}$ Just as adults may engage in risk behaviours following stress, ${ }^{22}$ children may be exposed to additional risks (such as passive smoking, poor diet, physical inactivity or premature cessation of breast feeding) if parents altered their own lifestyle because of bereavement, which in turn impacts their children. However, the death of a relative may have further consequences for children. Other changes may also occur following bereavement, including reduced economic resources, changes in $\operatorname{care}^{23}$ or a change in parents' ability to fulfill parental roles owing to their own grief. ${ }^{24}$ Another difference is that young children lack an understanding about the consequences of death, ${ }^{24}$ and therefore the experiences of psychological stress following bereavement may vary compared with adults and between age groups in childhood.

We investigated the association between bereavement in early life and the subsequent risk of childhood cancers. We hypothesised that that risks would be of a larger magnitude following the death of a close relative versus the death of other relatives, and sudden death versus other death. ${ }^{6}{ }^{21}$ In addition, we hypothesised that risks would vary with timing of the exposure, owing to differences in awareness of $\operatorname{loss}^{24}$ and susceptibility to changes in family structure. ${ }^{23} 24$

\section{MATERIALS AND METHODS}

\section{Study participants and follow-up}

This population-based cohort study used data from Danish and Swedish national registers and its design has been described elsewhere. ${ }^{25}$ In brief, the unique civil personal registration number, which is assigned to all live-born children and new residents, was used to link children to their relatives and to information on birth, death, demographics, social data and various health outcomes from different national registers. Children of mothers with no personal registration number recorded were excluded as they could not be linked to their relatives $(\mathrm{n}=10641 ; 0.17 \%)$. Additionally, children diagnosed with cancer within 3 months and 12 months of birth were excluded, to remove cancers likely to have been prevalent at birth $(n=348 ; 0.01 \%)$. The remaining study populations included 2729308 children from Denmark and 3395166 children from Sweden.

The exposure for the study is bereavement by the death of a close relative. Children born in Denmark from 1968 to 2007 and in Sweden from 1973 to 2006 were linked to their relatives (parents, siblings, mother's siblings and mother's parents) by their personal registration number, using the Danish Civil Registry System and the Swedish Multigeneration Register. Data on relatives' deaths were obtained from the Danish Civil Registry and the Swedish Cause of Death Registry. Follow-up started at birth when all children were classified as 'unexposed'. Children would be categorised as 'exposed' when they experienced the death of a close relative, and afterwards contributed observation time for the exposed group. Follow-up ended at the first of the following events: date of a cancer diagnosis, death, emigration, day before their 15th birthday or end of follow-up (31 December 2006 in Sweden and 31 December 2007 in Denmark). Covariates were selected a priori according to the previous literature: potential confounders at the baseline (birth) included maternal age $(\leq 26,27-30$ and $>30$ years), parity ( 1,2 and $\geq 3)$, multiplicity, maternal education level at birth $(\leq 9,10-14$ and $>15$ years $)$ and maternal smoking during pregnancy. Data on covariates were obtained from the Medical Birth Registries, the Swedish Education Register and the Danish Integrated Database for Labour Market Research.

The data on all incident cancers (ICD-7 codes 104-205, ICD-10 codes C00-97) diagnosed up to the 15th year of age were obtained from the Swedish and Danish National Cancer Registries. ${ }^{26} 27$ Additionally, specific childhood cancer diagnoses previously suggested to be related to stress, hormones or immune status were considered, including testicular cancer (ICD-7 178, ICD-10 C62), ${ }^{28}$ leukaemias (ICD-7 204, ICD-10 C91-95) ${ }^{29} 30$ or lymphomas (Hodgkin's lymphoma (ICD-7 201, ICD-10 C81) and non-Hodgkin's lymphoma (ICD-7 200 and 202, ICD-10 C82-83)). ${ }^{21} 3031$ As there is limited evidence on childhood cancer aetiology, we also included central nervous system (CNS) tumours (ICD-7 193, ICD-10 C70-72) and Wilms' tumour (ICD-7 180, ICD-10 C69.2).

\section{Statistical analysis}

Statistical analyses were carried out using Stata 11. HRs with $95 \%$ CIs were estimated using the Cox regression model, accounting for some mothers having more than one child with robust estimation. Proportional-hazards assumption was evaluated using the estat phtest function, which tests the assumption on the basis of Schoenfeld residuals. The analyses were stratified by type of bereavement (the death of a parent/sibling, or of another relative: mother's parents or mother's siblings), cause of death (unexpected death owing to an accident, suicide or violence or other death) and timing of the exposure (age at exposure $0-1,2-5,6-9$ or $10-14$ years)..$^{20} 3233$ Potential confounders (country, maternal age, parity and multiplicity) were adjusted for. Additionally, 
stratification was carried out by sex, country, birth weight, 5 min Apgar score and gestational age of the children to assess for effect measure modification: children born with low or high birth weight, preterm with a low Apgar score, may be more susceptible to suffer severe health consequences of hazardous exposures early in life, such as stress. In subanalyses, we also adjusted for data on smoking during pregnancy (which were available from 1991 onwards in Denmark and from 1983 onwards in Sweden) and maternal education at child birth (available from the start of the data in Sweden (1973), but from 1980 onwards in Denmark). These were considered to be possible confounders, but were only available for limited periods and had a relatively high proportion of missing values. Therefore, they were included only in subanalyses to assess whether they altered the results. Birth year was added to adjust for calendar time. To check for the possibility of confounding by a genetic predisposition to cancer, the analyses were repeated following the exclusion of children whose bereavement was caused by death of a parent from cancer. Additionally, analyses were carried out where children were moved to the exposed group 3 months and then 12 months after they experienced a death of a relative, to allow some time for a potential physiological effect of the bereavement. Finally, multiple imputations were carried out for missing covariates using Stata's ice command. Maternal origin, birth year, birth weight and gestational age were also included in the imputation model.

\section{RESULTS}

Of the 6124474 children, 1505938 (24.5\%) experienced death of a relative during the follow-up period of 71.9 million person-years. In the cohort, 9823 children were diagnosed with cancer (incidence rate 13.7/ 100000 person-years), the most common being leukaemias (2882), cancers of the CNS (2546) and Wilms' tumours (606). Of children exposed to death of a relative, 1350 received a diagnosis of childhood cancer.

The characteristics of the study population are provided in table 1 . Children in the exposed group were more likely to have low birth weight, to be of higher birth order and to be born to mothers who were older, of Nordic origin, with lower education levels and who more often reported smoking during pregnancy. Additionally, children in the exposed cohort were more likely to have a low Apgar score at 5 min (table 1).

The associations between bereavement and childhood cancer are displayed in table 2. Compared with unexposed children, exposed children had a slightly increased cancer risk (HR 1.10; 95\% CI 1.04 to 1.17). When stratifying by the type of relative, the association between parent/sibling death and childhood cancers was positive, but statistically insignificant. For more distant relatives, the association was smaller, but statistically significant. The association was also significant for who experienced the death of a relative owing to a disease and for those bereaved between 2 and 5 years of age (table 2). Adding birth year, maternal smoking during pregnancy and maternal education at birth to the models did not alter the results (data not shown).

When we excluded children exposed to the death of a parent from cancer $(n=31737)$, the overall risk of childhood cancer related to loss of a relative was almost unchanged (HR 1.09; 95\% CI 1.03 to 1.16 ); if the death was because of a disease, the HR $(95 \% \mathrm{CI})$ was 1.10 (1.04 to 1.18). Moving children to the exposed group 3 months (HR 1.09; 95\% CI 1.03 to 1.16 ) or 12 months (HR 1.08; 95\% CI 1.01 to 1.16 ) after they experienced the death of a relative also gave similar results. Following imputation of missing data, results were not greatly altered: the HR (95\% CI) was 1.13 (1.07 to 1.20).

Stratified analyses were carried out to assess for effect measure modification by sex, birth weight (low $<2500 \mathrm{~g}$, normal 2500-3999 g, high $\geq 000 \mathrm{~g}$ ), gestational age (preterm $<37$ weeks, term $\geq 37$ weeks) or 5-min Apgar score (low $<7$, normal $7-10$ ). The estimates for each strata did not differ significantly, so significant effect modification was not observed, but exposure groups became small for these analyses. Additionally, the data were stratified by country to see if the association was different in the two countries. While CIs for the HRs overlapped, the association between exposure and childhood cancer was slightly larger for Sweden (HR 1.12; $95 \%$ CI 1.03 to 1.20) than for Denmark (HR 1.07; 95\% CI 0.97 to 1.19 ).

The associations between bereavement and specific childhood cancers are shown in table 3. A number of cases were particularly small for testicular cancer and Hodgkin's lymphoma, and for exposure subgroups; results from subgroups are therefore not displayed. Those exposed were observed to have a significantly increased risk for CNS tumours (HR 1.14; 95\% CI 1.02 to 1.28$)$. A positive association was also seen for leukaemia (HR 1.12; 95\% CI 1.00 to 1.26) (table 3).

\section{DISCUSSION}

In this large population-based cohort study, a small but statistically significant overall increased risk of childhood cancer was observed among children exposed to bereavement owing to the death of a family member. Exposure was also associated with CNS tumours and leukaemia. However, limited number of cases prevented us from obtaining informative estimates for most of specific childhood cancers. Whether this is causally related to the stress exposure or a consequence of other factors is unknown.

The main methodological strength of the study is the use of the large, longitudinal, nationwide registers from Denmark and Sweden. Data were collected prospectively and is of high quality, with almost a complete follow-up. ${ }^{34}$ Although childhood cancers are a leading cause of childhood death in affluent countries, they are not very common, making ad hoc follow-up studies rare. 
The cancer registries have high levels of completeness. ${ }^{26}{ }^{27}$ Bereavement owing to the death of a relative is considered one of the most stressful life events, ${ }^{20}$ irrespective of coping style. ${ }^{35}$

A limitation is the uncertainty of induction and latency periods for childhood cancer. The main analysis was therefore repeated twice considering the start of exposure to be 3 months or 1 year after they had experienced the bereavement, allowing some time for a potential physiological effect of the bereavement. This did not provide different results. Future research may suggest more evidence-based lag times for childhood cancer

Table 1 Descriptive statistics of the study population

\begin{tabular}{|c|c|c|c|}
\hline Variables & $\begin{array}{l}\text { Exposed cohort } \\
(n=1426013) n(\%)\end{array}$ & $\begin{array}{l}\text { Unexposed cohort } \\
(n=6123531) n(\%)\end{array}$ & p Value \\
\hline \multicolumn{4}{|l|}{ Sex } \\
\hline Male & $773690(51)$ & $3143231(51)$ & \\
\hline Female & 732244 (49) & $2980280(49)$ & \\
\hline Missing & $4(<1)$ & $20(<1)$ & 0.564 \\
\hline \multicolumn{4}{|l|}{ Birth weight* $(g)$} \\
\hline$<2500$ & $68125(5)$ & 232387 (4) & \\
\hline 2500-3999 & 1119223 (77) & $4024314(75)$ & \\
\hline$\geq 4000$ & 250538 (17) & 914659 (17) & \\
\hline Missing & $22344(2)$ & $215793(4)$ & $<0.01$ \\
\hline \multicolumn{4}{|l|}{ Maternal age } \\
\hline$\leq 26$ & 519495 (35) & 2398883 (39) & \\
\hline $27-30$ & $443592(30)$ & $1777990(29)$ & \\
\hline$\geq 31$ & $542782(36)$ & $1946022(32)$ & \\
\hline Missing & $69(<1)$ & $636(<1)$ & $<0.01$ \\
\hline \multicolumn{4}{|c|}{ Gestational age (weeks)* } \\
\hline$<37$ & $82407(6)$ & $82407(6)$ & \\
\hline$\geq 37$ & 1351860 (93) & $1351860(93)$ & \\
\hline Missing & $25961(2)$ & $25961(2)$ & $<0.01$ \\
\hline \multicolumn{4}{|l|}{ Parity† } \\
\hline 1 & $582558(41)$ & $2648077(46)$ & \\
\hline 2 & $519142(37)$ & 2030259 (35) & \\
\hline$\geq 3$ & 305963 (22) & $1059912(18)$ & \\
\hline Missing & $806(<1)$ & $10633(<1)$ & $<0.01$ \\
\hline \multicolumn{4}{|c|}{ Maternal education $\ddagger$ (years) } \\
\hline Low, $\leq 9$ & 701579 (49) & $2306817(44)$ & \\
\hline Middle, $10-14$ & $398797(28)$ & $1461584(28)$ & \\
\hline High, $\geq 15$ & $296247(21)$ & $1046192(20)$ & \\
\hline Missing & 44454 (3) & $442534(8)$ & $<0.01$ \\
\hline \multicolumn{4}{|c|}{ Maternal smoking during pregnancy§ } \\
\hline Yes & $222980(26)$ & 703266 (19) & \\
\hline No & $572800(66)$ & $2674088(72)$ & \\
\hline Missing & $69925(8)$ & $315934(9)$ & $<0.01$ \\
\hline \multicolumn{4}{|l|}{ Singleton† } \\
\hline Yes & $1437016(97)$ & $5451148(95)$ & \\
\hline No & $39129(3)$ & $147173(3)$ & \\
\hline Missing & $10030(1)$ & $150560(3)$ & $<0.01$ \\
\hline \multicolumn{4}{|c|}{ Apgar score at $5 \mathrm{~min}^{*}$} \\
\hline Low, 0-6 & $13960(1)$ & $52667(1)$ & \\
\hline Normal, 7-10 & 1352106 (93) & $4946721(92)$ & \\
\hline Missing & $94162(6)$ & $387762(7)$ & $<0.01$ \\
\hline \multicolumn{4}{|l|}{ Country } \\
\hline Denmark & $663820(44)$ & $2728862(45)$ & \\
\hline Sweden & $842118(56)$ & 3394669 (55) & $<0.01$ \\
\hline \multicolumn{4}{|l|}{ Maternal origin } \\
\hline Nordic & 1482681 (99) & $5758361(94)$ & \\
\hline Non-Nordic & 19532 (1) & 333804 (6) & \\
\hline Missing & $3725(<1)$ & 31366 (1) & $<0.01$ \\
\hline
\end{tabular}


Table 2 HR for all childhood cancers according to exposure status

\begin{tabular}{|c|c|c|c|}
\hline Bereavement & $\begin{array}{l}\text { Cancer cases (rate 1/100 } 000 \\
\text { person-years) }\end{array}$ & Crude HR & Adjusted HR $(95 \% \mathrm{Cl})^{*}$ \\
\hline All exposed & $1350(13.88)$ & 1.15 & 1.10 (1.04 to 1.17$)$ \\
\hline \multicolumn{4}{|c|}{ Type of deceased relative } \\
\hline Parent/sibling & $140(14.44)$ & 1.20 & $1.18(0.99$ to 1.41$)$ \\
\hline Other relatives & 1210 (13.82) & 1.14 & 1.09 (1.03 to 1.16$)$ \\
\hline \multicolumn{4}{|l|}{ Cause of death } \\
\hline Unexpected & $132(12.83)$ & 1.06 & $1.03(0.87$ to 1.23$)$ \\
\hline Other & $1217(14.07)$ & 1.16 & $1.11(1.04$ to 1.19$)$ \\
\hline \multicolumn{4}{|c|}{ Age at exposure (years) } \\
\hline $0-1$ & $350(14.88)$ & 1.10 & $1.06(0.95$ to 1.18$)$ \\
\hline $2-5$ & $536(13.88)$ & 1.17 & 1.13 (1.03 to 1.23$)$ \\
\hline $6-9$ & $306(12.48)$ & 1.13 & $1.08(0.95$ to 1.21$)$ \\
\hline $10-14$ & $158(14.88)$ & 1.17 & 1.14 (0.99 to 1.39$)$ \\
\hline Unexposed & $8473(13.64)$ & 1.0 (ref) & 1.0 (ref) \\
\hline
\end{tabular}

research. Compared with the unexposed group, there were fewer missing values for some covariates in the exposed group. This may partly be related to a higher proportion of children born to mothers of Nordic origin in the exposed group (98.5\% compared with $94.0 \%)$, as information for mothers of non-Nordic origin may be less complete. We did not have information on other stressful events, for example, parental divorce or the death of a caregiver. However, those who experienced other causes of stress would be categorised as 'unexposed', and such misclassification would probably draw risk estimates towards the null. Finally, despite a large sample size, case numbers for some specific cancers were small.

We have previously reported that mothers who experience the death of a child have increased cancer risk, ${ }^{6}$ and if mothers are exposed to bereavement during pregnancy, the risk of some childhood cancers in the offspring is increased. ${ }^{21}$ Considering the differences in the effects of stress in children compared to adults, we hypothesised variation in the size of the association based on age at bereavement, as there may be little awareness of a loss at a very young age. Although a significant increase in risk was seen following bereavement

Table 3 HR for specific childhood cancers according to bereavement

\begin{tabular}{|c|c|c|c|}
\hline Cancer & Cases (rate per 100000 person-years) & Crude HR & Adjusted HR (95\% Cl)* \\
\hline \multicolumn{4}{|l|}{ Leukaemias } \\
\hline Unexposed & $2522(4.06)$ & 1.0 (ref) & 1.0 (ref) \\
\hline All exposed & $360(3.70)$ & 1.2 & $1.12(1.00$ to 1.26$)$ \\
\hline \multicolumn{4}{|c|}{ Hodgkin's lymphoma } \\
\hline Unexposed & $123(0.20)$ & 1.0 (ref) & 1.0 (ref) \\
\hline All exposed & $43(0.44)$ & 1.29 & $1.17(0.81$ to 1.67$)$ \\
\hline \multicolumn{4}{|c|}{ Non-Hodgkin's lymphoma } \\
\hline Unexposed & $441(0.71)$ & 1.0 (ref) & 1.0 (ref) \\
\hline All Exposed & $68(0.70)$ & 1.03 & $0.99(0.76$ to 1.29$)$ \\
\hline \multicolumn{4}{|l|}{ CNS tumours } \\
\hline Unexposed & $2160(3.48)$ & 1.0 (ref) & 1.0 (ref) \\
\hline All exposed & 386 (3.97) & 1.19 & $1.14(1.02$ to 1.28$)$ \\
\hline \multicolumn{4}{|l|}{ Wilms' tumourt } \\
\hline Unexposed & $564(0.91)$ & 1.0 (ref) & 1.0 (ref) \\
\hline All exposed & $42(0.43)$ & 0.98 & $0.93(0.68$ to 1.28$)$ \\
\hline \multicolumn{4}{|c|}{ Testicular cancer } \\
\hline Unexposed & $50(0.08)$ & 1.0 (ref) & 1.0 (ref) \\
\hline All exposed & $5(0.05)$ & 1.16 & $1.08(0.41$ to 2.88$)$ \\
\hline
\end{tabular}


between the ages of 2-5 years, there were no significant differences between age groups. One potential reason is that bereavement, particularly of a close relative, can be a long lasting stressor leading to allostatic load, ${ }^{36}$ and not limited to the period immediately after bereavement. Other studies looking at stressful life events and malignant disease in adults have produced mixed results: some found no association, ${ }^{37-42}$ while some have reported increased risks. ${ }^{6} 7$ Most studies have included less severe stress exposures than the loss of a close relative, and similar to our findings, positive associations have generally been of modest magnitude, indicating that if stress is a causal factor it is only one of the many potential causes.

Although it is unlikely that bereavement increases risks for all childhood cancers, the observed associations suggest a role of hormonal disturbance perhaps as a general promoter. The function of immune cells following a stressful exposure may impair the ability to detect and deal with cancerous cells and eliminate infections. For example, in adults, stress may inhibit apoptosis. ${ }^{9}$ Bereavement during childhood has been described as a 'tolerable stress', which can be overcome with the right support, but may become 'toxic' if unmanaged. ${ }^{43}$ Thus, insufficient coping and limited social support may further lead to allostatic load prolonging the hormonal imbalance. Whether the associations reflect a direct causal effect of stress or an indirect effect, mediated by other changes (eg, diet, infections or family dynamics), or are a result of unadjusted confounding is not known. We do not know more than a small fraction of childhood cancer causes, making confounder adjustments far from complete. We had expected that any observed increases in childhood cancer in the exposed group to be related to increases in cancers related to hormone and immune status. While an increase was seen for leukaemias, it was also seen for CNS tumours, which was not based on an a priori hypothesis. However, the "two-hit theory ${ }^{44}$ and multistep theory ${ }^{45}$ of carcinogenesis suggest that at least two mutagenic hits are necessary for cancer development; research has suggested that some childhood cancers, including leukaemias ${ }^{46}$ and CNS tumours, ${ }^{47}$ are initiated in utero. If psychological stress does affect childhood cancer risk, bereavement may act as or facilitate the second 'hit'. The need for exposure to a risk factor during gestation to initiate the development of a childhood cancer and the vast number of other potential causes of 'hits' could explain the relatively small association seen in this study, for cancers which have been suggested to be initiated in utero.

If stress has a causal relation with certain childhood cancers, it would be expected to vary with the intensity of stress. However, stress is a 'highly individualistic experience', ${ }^{48}$ which may make it difficult to consider a dose-response effect. The risk of childhood cancer was not higher in those who lost a parent or a sibling than in those who lost a more distant relative. Additionally, there were no differences in risk if the loss was sudden or because of a disease, but the numbers become small for these sub-analyses. It is also difficult to hypothesise, especially in this age group, which would cause a greater level of stress: an unexpected loss or loss from a chronic disease. A long-term effect may be more important, which follow either types of loss.

Our data suggest that psychological stress in early life is associated with an increased risk of some childhood cancers. Early life bereavement may also have long-term effects on cancer risk. For example, epigenetic changes or impairment of DNA repair may reduce the body's ability to deal with the future carcinogenic exposures. $^{8} 1213$ Inclusion of data from more countries or over a longer time period could provide greater power to better assess the association between stress and specific cancers. The association between early life stress and childhood cancer was small, but adds to our general understanding of the causes and development of childhood cancers.

Contributors JL and JO conceived the research. NCM analysed the data and wrote the first draft of the manuscript. NCM, JO, SC, MG and JL contributed to data analysis, interpretation of results and critical revision of the manuscript.

Funding This work was supported by a grant from the European Research Council (ERC-2010-StG no. 260242, the EC's Seventh Framework Programme for Research (FP7)); and the Nordic Cancer Union (2008, 2013); and the NordForsk (070331); the Danish Medical Research Council (projects no. 09-060229, 09-063494 and 09-072986); and the Swedish Council for Working Life and Social Research (grant no. 2010-0092).

\section{Competing interests None.}

Ethics approval Danish Data Protection Agency (j nr. 2008-41-2680), Scientific Ethics Committee of Central Jutland Region (VEK, sagnr. M-20100252) and the Research Ethic Committee (EPN) at the Karolinska Institute (Ref no. 2008/4:6).

Provenance and peer review Not commissioned; externally peer reviewed.

Data sharing statement The data are accessed via secure server at Statistics Denmark. We, the researchers, are unable to provide access to the raw data.

\section{REFERENCES}

1. Anderson LM. Environmental genotoxicants/carcinogens and childhood cancer: bridgeable gaps in scientific knowledge. Mutat Res 2006;608:136-56.

2. Kaatsch P. Epidemiology of childhood cancer. Cancer Treat Rev 2010;36:277-85.

3. Parkin DM, Whelan S, Ferlay J, et al. Cancer incidence in five continents VIII. IARC Scientific Publications. Vol. 155. Lyon, France: IARC, 2002.

4. Giles D, Hewitt D, Stewart A, et al. Malignant disease in childhood and diagnostic irradiation in utero. Lancet 1956;271:447.

5. Bross ID, Natarajan N. Leukemia from low-level radiation: identification of susceptible children. $N$ Engl J Med 1972;287:107-10.

6. Li J, Johansen C, Hansen D, et al. Cancer incidence in parents who lost a child: a nationwide study in Denmark. Cancer 2002;95:2237-42.

7. Hatch MC, Wallenstein S, Beyea J, et al. Cancer rates after the Three Mile Island nuclear accident and proximity of residence to the plant. Am J Public Health 1991;81:719-24.

8. Kiecolt-Glaser JK, Glaser R, Williger D, et al. Psychosocial enhancement of immunocompetence in a geriatric population. Health Psychol 1985;4:25-41.

9. Reiche EM, Nunes SO, Morimoto HK. Stress, depression, the immune system, and cancer. Lancet Oncol 2004;5:617-25.

10. Hunter RG. Epigenetic effects of stress and corticosteroids in the brain. Front Cell Neurosci 2012;6:18. 
11. Herceg Z, Vaissiere T. Epigenetic mechanisms and cancer: an interface between the environment and the genome. Epigenetics 2011;6:804-19.

12. Jones PA, Baylin SB. The fundamental role of epigenetic events in cancer. Nat Rev Genet 2002;3:415-28.

13. Klengel T, Mehta D, Anacker $C$, et al. Allele-specific FKBP5 DNA demethylation mediates gene-childhood trauma interactions. Nat Neurosci 2013;16:33-41.

14. Bearer CF. How are children different from adults? Environ Health Perspect 1995;103(Suppl 6):7-12.

15. Linet MS, Gridley G, Cnattingius S, et al. Maternal and perinatal risk factors for childhood brain tumors (Sweden). Cancer Causes Control 1996;7:437-48.

16. Arico M, Caselli D, D'Argenio $\mathrm{P}$, et al. Malignancies in children with human immunodeficiency virus type 1 infection. The Italian Multicenter Study on human immunodeficiency virus infection in children. Cancer 1991;68:2473-7.

17. Armstrong AA, Alexander FE, Paes RP, et al. Association of Epstein-Barr virus with pediatric Hodgkin's disease. Am J Pathol 1993;142:1683-8.

18. Dockerty JD, Skegg DC, Elwood JM, et al. Infections, vaccinations, and the risk of childhood leukaemia. Br J Cancer 1999:80:1483-9.

19. Harrington R, Harrison L. Unproven assumptions about the impact of bereavement on children. J R Soc Med 1999;92:230-3.

20. Skodol AE, Shrout PE. Use of DSM-III axis IV in clinical practice: rating etiologically significant stressors. Am J Psychiatry 1989;146:61-6.

21. Li J, Vestergaard M, Obel C, et al. Antenatal maternal bereavement and childhood cancer in the offspring: a population-based cohort study in 6 million children. Br J Cancer 2012;107:544-8.

22. Cohen S, Rabin BS. Psychologic stress, immunity, and cancer. J Natl Cancer Inst 1998;90:3-4.

23. Wolchik SA, Tein JY, Sandler IN, et al. Stressors, quality of the child-caregiver relationship, and children's mental health problems after parental death: the mediating role of self-system beliefs. $J$ Abnorm Child Psychol 2006;34:221-38.

24. Sood AB, Razdan A, Weller EB, et al. Children's reactions to parental and sibling death. Curr Psychiatry Rep 2006;8:115-20.

25. Li J, Vestergaard M, Obel C, et al. Cohort profile: the Nordic Perinatal Bereavement Cohort. Int J Epidemiol 2011;40:1161-7.

26. Barlow L, Westergren $\mathrm{K}$, Holmberg L, et al. The completeness of the Swedish Cancer Register: a sample survey for year 1998. Acta Oncol 2009;48:27-33.

27. Gjerstorff ML. The Danish Cancer Registry. Scand J Public Health 2011;39(7 Suppl):42-5.

28. Bernstein L, Depue RH, Ross RK, et al. Higher maternal levels of free estradiol in first compared to second pregnancy: early gestational differences. J Natl Cancer Inst 1986;76:1035-9.

29. Levav I, Kohn R, Iscovich J, et al. Cancer incidence and survival following bereavement. Am J Public Health 2000;90:1601-7.

30. Little J. Epidemiology of childhood cancer. IARC Scientific Publications No. 149. Lyon, France: International Agency for Research on Cancer, 1999.
31. Bermejo JL, Sundquist J, Hemminki K. Risk of cancer among the offspring of women who experienced parental death during pregnancy. Cancer Epidemiol Biomarkers Prev 2007;16:2204-6.

32. American Psychiatric Association. Diagnostic and statistical manual of mental disorders. 4th edn. WashingtonDC: American Psychiatric Association, 2012

33. Stroebe MS, Hansson RO, Stroebe W, et al. Handbook of bereavement research: consequences, coping, and care. WashingtonDC: American Psychological Association, 2012.

34. Frank L. Epidemiology. When an entire country is a cohort. Science 2000;287:2398-9.

35. Goodkin K, Baldewicz T, Blaney N, et al. Physiological effects of bereavement and bereavement support group interventions. In: Stroebe M, Hansson R, Stroebe W, Chut H, eds. Handbook of bereavement research: coping, consequences, and care. WashingtonDC: American Psychological Association, 2001:671-703.

36. McEwen BS, Stellar E. Stress and the individual. Mechanisms leading to disease. Arch Intern Med 1993;153:2093-101.

37. Protheroe D, Turvey K, Horgan K, et al. Stressful life events and difficulties and onset of breast cancer: case-control study. BMJ 1999;319:1027-30.

38. Johansen $\mathrm{C}$, Olsen $\mathrm{JH}$. Psychological stress, cancer incidence and mortality from non-malignant diseases. Br J Cancer 1997;75:144-8.

39. Jones DR, Goldblatt PO, Leon DA. Bereavement and cancer: some data on deaths of spouses from the longitudinal study of Office of Population Censuses and Surveys. BMJ 1984;289:461-4.

40. Ewertz M. Bereavement and breast cancer. Br J Cancer 1986;53:701-3.

41. Kvikstad A, Vatten LJ. Risk and prognosis of cancer in middle-aged women who have experienced the death of a child. Int $J$ Cancer 1996;67:165-9.

42. Kvikstad A, Vatten LJ, Tretli S, et al. Death of a husband or marital divorce related to risk of breast cancer in middle-aged women. A nested case-control study among Norwegian women born 1935-1954. Eur J Cancer 1994;30A:473-7.

43. Middlebrooks JS, Audage NC. The effects of childhood stress on health across the lifespan. Atlanta, GA: Centers for Disease Control and Prevention, National Centre for Injury Prevention and Control, 2008.

44. Armitage P, Doll R. A two-stage theory of carcinogenesis in relation to the age distribution of human cancer. $\mathrm{Br} J$ Cancer 1957;11:161-9.

45. Vogelstein B, Kinzler KW. The multistep nature of cancer. Trends Genet 1993;9:138-41.

46. Wiemels JL, Xiao Z, Buffler PA, et al. In utero origin of t(8;21) AML1-ETO translocations in childhood acute myeloid leukemia. Blood 2002;99:3801-5.

47. Schmidt LS, Schuz J, Lahteenmaki $P$, et al. Fetal growth, preterm birth, neonatal stress and risk for CNS tumors in children: a Nordic population- and register-based case-control study. Cancer Epidemiol Biomarkers Prev 2010;19:1042-52.

48. Centre for Studies on Human Stress. How to measure stress in humans? Quebec, Canada: Centre for Studies on Human Stress, 2007. 